\title{
Bolus administration of esmolol for the treat- ment of intraoperative myocardial ischaemia
}

We report the successful treatment with esmolol of intraoperative myocardial ischaemia associated with concurrent hypertension and tachycardia, in a patient with risk factors for coronary artery disease undergoing peripheral vascular surgery. The pathophysiology of myocardial ischaemia, and the therapeutic role of beta blocking drugs are briefly reviewed. Esmolol, a short-acting cardioselective beta blocking drug, was administered in a bolus of $1.5 \mathrm{mg} \cdot \mathrm{kg}^{-1}$, and resulted in prompt resolution of the haemodynamic abnormalities, with concomitant restitution of the ST segments to isoelectric baseline. We conclude that bolus administration of esmolol is practical and can be effective for the treatment of intraoperative myocardial ischaemia.

Key words

ANAESTHESIA: general; HEART: ischaemia; MONITORING: electrocardiography; SYMPATHETIC NERVOUS SYSTEM: beta-adrenergic and antagonists.

From the Department of Anaesthesia, Ottawa General Hospital and the University of Ottawa, Ottawa, Ontario.

Address correspondence to: Dr. Donald R. Miller, Department of Anaesthesia, Ottawa General Hospital, 501 Smyth Road, Ottawa, Ontario K1H 8L6.
Perioperative myocardial ischaemia (PMI) in patients with known coronary artery disease (CAD) or two or more CAD risk factors is now known to occur with a much higher frequency than was previously recognized.' This may be due, in part, to more sensitive methods of ischaemia detection (improved ECG monitors, S-T segment trending, 2-D transoesophageal echocardiography), and also to the increasingly higher-risk patient population presenting for non-cardiac surgery. Recent evidence suggests a significant correlation exists between intraoperative myocardial ischaemia and postoperative myocardial infarction following coronary bypass surgery. ${ }^{2}$ Thus the early recognition and treatment of intraoperative myocardial ischaemia is important and, although unproven, may reduce the incidence of postoperative cardiac events (non-fatal myocardial infarction, congestive heart failure, or death).

Rational treatment of myocardial ischaemia should take into consideration the underlying mechanism of the ischaemia. Perioperative myocardial ischaemia related to increased myocardial oxygen consumption secondary to hypertension and tachycardia, may be treated by ensuring an appropriate depth of anaesthesia, and the use of beta-blocking sympathetic drugs. The following case report describes the prompt resolution of an episode of PMI, associated with concurrent hypertension and tachycardia following bolus administration of the new cardioselective beta-blocking drug, esmolol.

\section{Case report}

A 68-year-old male, $75 \mathrm{Kg}$ diabetic patient, with peripheral vascular disease, presented for an in situ profundoplasty for treatment of an ischaemic right foot. He had a past medical history of non-insulin dependent diabetes mellitus controlled by diet and oral hypoglycaemic drugs. Vascular reconstructive surgery had previously been done on his left leg, but failed, and his left foot was amputated one year before the current admission.

He had smoked 60 cigarettes per day for 40 years, but denied symptoms of respiratory disease. He had no angina or history of previous myocardial infarction. At the time of admission, his only medication was diabeta $5 \mathrm{mg} P O$ bid. 


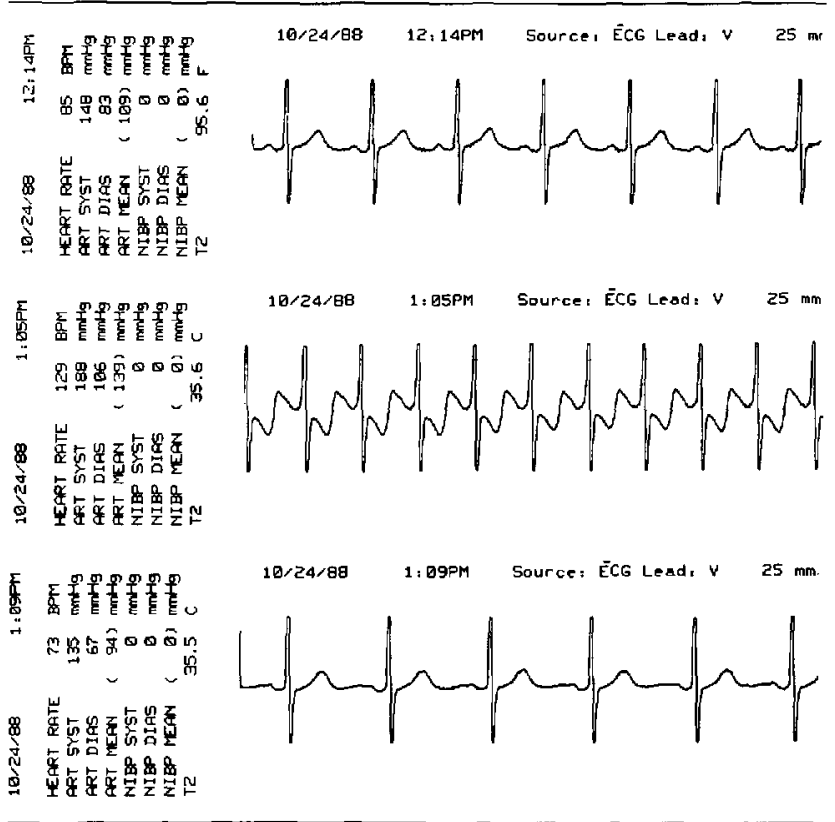

FGGURE 1 Haemodynamic data and $V_{5}$ tracing. The upper panel displays the normal ECG

recording and haemodynamic variables during surgery. A hypcrtensive response with ST depression is presented in the middle panel. Within four minutes of esmolol administration, the blood pressure and heart rate were normal, and the ST segments had returned to baseline (lower pane]).

On examination, his blood pressure was $160 / 95 \mathrm{mmHg}$ and the heart rate was 90 BPM and regular. Cardiac examination revealed a normal S1 and S2, No S3, S4 or murmurs were present. His chest was clear to auscultation. He had an erythematous right foot and a pregangrenous right great toe, as well as a left below knee amputation. His preoperative investigations revealed a haemoglobin of $126 \mathrm{~g} \cdot \mathrm{L}^{-1}$, fasting blood glucose 11.3 $\mathrm{mmol} \cdot \mathrm{L}^{-1}$ and normal serum electrolyte concentrations. The preoperative ECG was normal and the chest $x$-ray showed mild left ventricular enlargement.

The patient gave written, informed consent to the institutionally approved protocol investigating preinduction administration of esmolol to attenuate haemodynamic responses to tracheal intubation. Accordingly, esmolol was available for this patient, although the current case report describing the intraoperative bolus administration of esmolol was not related to any study protocol. Diabeta was withheld on the morning of surgery, and the patient was premedicated with diazepam, $15 \mathrm{mg} P O, 90 \mathrm{~min}$ preoperatively. In the operating room a large bore intravenous and radial arterial catheter for blood pressure monitoring was inserted under local anaesthesia prior to induction of anaesthesia. Electrocardiographic leads 11 and $V_{5}$ were monitored using a Spacelab Monitor Model 90651, at a calibration of 10 $\mathrm{mm} \cdot \mathrm{mV}^{-1}$. Recording strips were taken serially during the procedure. Inspired and end-tidal concentrations of anaesthetic and respiratory gases were monitored using a mass spectrometer. Oxygen saturation greater than 96 per cent was documented throughout the procedure by pulse oximetry.

In spite of esmolol $1.5 \mathrm{mg} \cdot \mathrm{kg}^{-1}$ which had been given prior to induction of anaesthesia with fentanyl $150 \mu \mathrm{g} \mathrm{IV}$, thiopentone $250 \mathrm{mg}$ IV titrated to loss of consciousness, and succinylcholine $120 \mathrm{mg}$ IV to facilitate tracheal intubation, the blood pressure and heart rate increased to $219 / 123 \mathrm{mmHg}$ and $116 \mathrm{BPM}$, respectively. An additional bolus of esmolol, $1.5 \mathrm{mg} \cdot \mathrm{kg}^{-1}$ IV was administered, and within three minutes the haemodynamic responses returned to pre-induction values $(156 / 90 \mathrm{mmHg}, 89$ BPM). There were no ischaemic ST segment changes during this period (Figure, upper panel). Maintenance of anaesthesia consisted of 70 per cent nitrous oxide with 
axygen, isoflurane $0.5-1.3$ per cent end-tidal, alfentanil administered intermittently (total dose $6.0 \mathrm{mg}$ ) and vecuronium as required to maintain muscle relaxation. The intraoperative course was characterized by several transient episodes of moderate hypertension in response to the skin incision and subsequent surgical stimulation. Towards the end of the first hour of surgery, the groin incision was extended, and the systemic blood pressure suddenly increased to $188 / 106$ accompanied by an increase in heart rate to $129 \mathrm{BPM}$, and $2.5 \mathrm{~mm}$ ST segment depression (J point $+80 \mathrm{msec}$ calibrated at $10 \mathrm{~mm} / \mathrm{mV}$ ) in precordial lead $\mathrm{V}_{5}$ (Figure, middle panel). At this time, the end-tidal isoflurane concentration was 0.7 per cent with 68 per cent end-tidal $\mathrm{N}_{2} \mathrm{O}$ in oxygen, and the oxygen saturation and end-tidal $\mathrm{CO}_{2}$ were 98 per cent and 30 $\mathrm{mmHg}$ respectively. The concentration of anaesthetic gases was kept constant and the patient was treated with esmolol $1.5 \mathrm{mg} \cdot \mathrm{kg}^{-1} \mathrm{IV}$ over $30 \mathrm{sec}$. Within four minutes of esmolol administration, the blood pressure and heart rate returned to normal $(135 / 67 \mathrm{mmHg}$ and $73 \mathrm{BPM}$ respectively) and the $S T$ segment in lead $V_{5}$ returned to an isoelectric baseline (Figure, lower panel) and remained unchanged compared with post-induction baseline. At the end of the procedure the muscle relaxant was reversed, the trachea was extubated when the patient was awake, and he was monitored overnight in the recovery room. Serial 12 lead ECGs were normal, and the peak creatinine kinase was $58 \mu \mathrm{mol}^{-1}$ on the first postoperative day, which ruled out a recent myocardial infarction. The patient had no further hypertensive episodes, and was discharged to the ward on the first postoperative day, and from hospital six days following surgery.

\section{Discussion}

We attributed the "hyperdynamic responsiveness" of this patient to his history of moderate preoperative hypertension, and to his diabetes, which is known to result in a relative degree of autonomic instability. Although our patient did not have a history of CAD, he did have important risk factors, including peripheral vascular disease, diabetes, a long history of smoking, and hypertension. In such patients, the incidence of CAD detected by routine preoperative coronary angiography is approximately 30 per cent. ${ }^{3}$ Furthermore, the incidence of PMI is also significant, as reported by the Study of Perioperative Ischaemia Research Group. Using continuous 12-lead electrocardiography, this group recently demonstrated that 24 per cent of patients with either diagnosed CAD or two or more CAD risk factors develop PMI during non-cardiac surgery. ${ }^{1}$ Therefore, because of our heightened suspicion, we elected to monitor both leads $V_{5}$ and 11 in order to obtain a high degree of sensitivity. Using this monitoring, an episode of marked ST segment depression was observed. The downsloping configuration of the ST segment change was typical of an ischaemic episode. This electrocardiographic interpretation was subsequently confirmed by a cardiologist. This is the first description in man of the successful treatment of such an intraoperative myocardial ischaemic event using bolus administration of the new, short-acting beta-blocking drug esmolol.

It has recently been suggested that PMI is often unrelated to haemodynamic abnormalities, ${ }^{2,4,5}$ and may result from coronary artery spasm. This has been defined as a supply type of ischaemia. ${ }^{6}$ Similarly, a demand type of myocardial ischaemia has also been defined, which exists when coronary blood flow cannot increase, because of stenosis, to meet increases in myocardial oxygen demand. In our case, the ischaemic event observed was likely caused by an increase in myocardial oxygen demand, directly through an increase in heart rate and indirectly through increased systemic pressure, in a patient with underlying CAD. In fact, the rate-pressure product (RPP), an index of myocardial oxygen consumption, increased two-fold, from 12,500 to 24,200 during this hypertensive response to surgical stimulation. Since the patient had been haemodynamically stable, with appropriate anaesthetic depth before the ischaemic event, we chose to administer a bolus of $1.5 \mathrm{mg} \cdot \mathrm{kg}^{-1}$ esmolol to treat both the ischaemia and untoward haemodynamic response. This treatment proved successful with control of heart rate and blood pressure within four minutes and caused a rapid reversal of ST depression seen on the ECG.

Beta blocking drugs are effective in treating myocardial ischaemia by reducing myocardial oxygen consumption $\left(\mathrm{MVO}_{2}\right)$ and sympathetic tone. ${ }^{7}$ In addition, a slower heart rate increases diastolic filling time, and hence coronary blood flow. Beta-blocking drugs may also change the substrate of the myocardial cells by blocking catecholamine-induced increases in fatty acid utilization, with a shift to carbohydrate metabolism and thereby, a reduced oxygen consumption. ${ }^{8,9}$ The beneficial effects of beta-blocking drugs on the ischaemic myocardium have justified continuing these drugs until surgery in patients with CAD. Recent evidence also suggests that chronically beta-blocked patients undergoing CABG have a lower incidence of PMI compared with patients treated with calcium entry blockers. ${ }^{10}$ Despite such evidence, the myocardial protective effect of acute intraoperative betasympathetic blockade has not yet been clearly established.

Compared with the longer-acting propranolol, esmolol is a cardioselective beta blocker with a rapid onset of action and a very short elimination half-life of nine minutes. " Previous studies have demonstrated the efficacy of continuous infusions of esmolol for controlling perioperative hypertension and tachycardia with a variety of anaesthetic techniques. ${ }^{12-15}$ The efficacy of esmolol 
infusion has also been studied in animals and it has been shown to improve myocardial function following reperfusion after three hours of coronary artery occlusion in dogs. ${ }^{16}$ Esmolol may also reduce myocardial infarct size in addition to improving post-ischaemic recovery of myocardial function. ${ }^{17}$ Esmolol infusion during the acute and recovery phases of acute myocardial infarction has also been investigated and reported to be safe in humans. ${ }^{18}$ In our case, esmolol was efficacious for the treatment of PMI without associated myocardial infarction.

Our rationale for the administration of esmolol as a bolus rather than as an infusion was the requirement for a rapid onset and short duration of action, in order to treat promptly a transient intraoperative event. The convenience of bolus administration compared with the preparation and administration of an infusion facilitated prompt initiation of therapy. Bolus administration of esmolol has previously been shown to be safe and effective in the range of $1.0-3.0 \mathrm{mg} \cdot \mathrm{kg}^{-1}$. Comparing bolus administration with an infusion, a minimal prolongation of the $P R$ interval and a 13-20 per cent decrease in blood pressure are seen in this dosage range. ${ }^{19,20}$

We observed that the hypertensive response to intubation was not associated with ischaemic ECG changes in contrast to the response during surgery, despite similar estimated increases in $\mathrm{MVO}_{2}$. At a lower heart rate, but higher systolic blood pressure, the peak RPP postintubation was almost identical to that observed during the ischaemic event $(24,400$ compared with 24,200 , respectively). The absence of ischaemia at induction of anaesthesia may have been partly due to the $1.5 \mathrm{mg} \cdot \mathrm{kg}^{-1}$ boluses of esmolol which had been administered prior to induction and immediately after intubation. By controlling heart rate responses, esmolol may have been "protective" in preventing the development of ischaemia.

Finally, alternative modes of therapy were considered for treatment of the event. Increasing the concentration of the inhalation anaesthetic would have controlled the pressor response, but in view of the coincidental ischaemia, a greater concentration of isoflurane might have had a further deleterious effect on the coronary circulation. ${ }^{21,22}$ Bolus administration of a narcotic might have been useful, but would likely have had a slower onset of action. Further, narcotics do not offer the protective effect of the beta blocking drugs on the ischaemic myocardium. Because the depth of maintenance anaesthesia had been appropriate before the ischaemic event, and because of our concerns of alternative treatment modalities, bolus administration of esmolol was used for the concomitant treatment of hypertension, tachycardia, and myocardial ischaemia.

\section{References}

1 London $M$, Hollenberg $M$, Wong $M$ et al. Intraoperative myocardial ischaemia: localization by continuous 12-lead electrocardiography. Anesthesiology 1988; 69: 232-41.

2 Slogoff S, Keats AS. Does perioperative myocardial ischaemia lead to postoperative myocardial infarction? Anesthesiology 1988; 62: 107-14.

3 Hertzer $N$, Beven E, Young J et al. Coronary artery disease in peripheral vascular patients. Ann Surg 1984; 223-33.

4 Deanfield JE, Selwyn AP. Character and causes of transient myocardial ischaemia during daily life. Am J Med 1986; 80 (Suppl 4C): 12-8.

5 Knight AA, Hollenberg M, London MJ et al. Perioperative myocardial ischaemia: Importance of the perioperative ischaemic pattern. Anesthesiology 1988; 68: 681-8.

6 Cohn PF. Total ischaemic burden: definition, mechanisms, and therapeutic implications. Am J Med 1986; 81 (Suppl 4): 2-6.

7 McIntyre RW, Reves JG. Intraoperative management of acute ischaemia. In: Thomas SJ (Ed.). Problems in Anaesthesia; Cardiovascular Anesthesia. Philadelphia, Lippincott, 1987; 359-77.

8 Opie LH, Thomas $M$. Propranolol and experimental myocardial infarction. Substrate effects. Postgrad Med J 1976; 52 (Suppl): 124.

9 Prichard BNC. $\beta$-adrenoceptor blocking agents. Abshagen (Ed.). Clinical Pharmacology of Antiangina, New York, Springer-Verlag, 1985; 76: 385.

10 Chung F, Houston P, Cheng D et al. Calcium channel blockade does not offer adequate protection from perioperative myocardial ischaemia. Anesthesiology 1988; 69: 343-7.

11 Sum CY, Yacobi A, Kartzinel $R$ et al. Kinetics of esmolol, an ultra short-acting beta blocker and its major metabolites. Clin Pharmacol Ther 1983; 34: 427-34.

12 Menkhaus PG, Reves JG, Kissin I. Cardiovascular effects of esmolol in anaesthetized humans. Anesth Analg $1985 ; 64: 327-32$.

13 Girard D, Shuiman BJ, Thys DM et al. The safety and efficacy of esmolol during myocardial revascularization. Anesthesiology 1986; 65: 157-65.

14 Newsome LR, Roth $J V$, Hug CC et al. Esmolol attenuates hemodynamic responses during fentanyl-pancuronium anesthesia for aortocoronary bypass surgery. Anesth Analg 1986; 65: 451-6.

15 Harrison $L$, Ralley $F$, Wynands $J$ et al. The role of the ultra-short-acting adrenergic blocker (esmolol) in patients undergoing coronary artery bypass surgery. Anesthesiology 1987; 66: 413-8. 
16 Lange $R$, Kloner $R$, Braunwald $E$. First ultra-short acting beta-adrenergic blocking agent: its effect on size and segmental wall dynamics of reperfused myocardial infarcts in dogs. Am J Cardiol 1983; 51: 1759-66.

17 Kloner $R$, Kirshenbaum $J$, Lange $R$ et al. Experimental and clinical observation of the efficacy of esmolol in myocardial ischaemia. Am J Cardiol 1985; 56: 40F.

18 Kirshanbaum J, Kloner R, Antman E, Braunwald E. Use of ultra short-acting $\beta$ blocker in patients with acute myocardial ischemia. Circulation 1985; 72: 873-9.

19 Sintetos AL, Hulse J, Pritchett EL. Pharmacokinetics and pharmacodynamics of esmolol administered as an intravenous bolus. Clin Pharmacol Ther 1987; 41: 112-7.

20 Ellenbogen KA, McCarthy EA, Pritchett ELC. Effects of bolus injection of esmolol in healthy exercising subjects. Clin Pharmacol Ther 1987; 41: 455-9.

21 Reiz $S$, Balfors $E$, Sorensen $M B$, Arida $S J r$, Friedman A, Truedsson $H$. Isoflurane - a powerful coronary vasodilator in patients with coronary artery disease. Anesthesiology $1983 ; 27: 464-9$.

22 Moffitt EA, Barker RA, Glenn JJ et al. Myocardial metabolism and hemodynamic responses with isoflurane anesthesia for coronary artery surgery. Anesth Analg 1984; 63: 252.
Résumé

Lors d' une chirurgie vasculaire périphérique, un de nos patients, a risque de maladie coronarienne, devint tachycarde et hypertendu avec des signes d'ischémie myocardique. Nous avons alors injecté une dose de $1.5 \mathrm{mg} \cdot \mathrm{kg}^{-1}$ d'esmolol, un $\beta$-bloqueur cardiosélectif de courte durée. L'esmolol cirrigea rapidement les perturbations hémodynamiques et les segments ST revinrent d la normale. Nous revoyons la physio-pathologie de l'ischémie myocardique et le rôle thérapeutique des $\beta$-bloqueurs et concluons que l'injection d' esmolol est pratique etpeut être bênéfique lorsd'épisodes per-opératoires d' ischémie myocardique. 